\title{
TASTE TRUMPS HEALTH AND SAFETY: INCORPORATING CONSUMER PERCEPTIONS INTO A DISCRETE CHOICE EXPERIMENT FOR MEAT
}

\author{
TREY MALONE* \\ Department of Agricultural Economics, Oklahoma State University, Stillwater, Oklahoma \\ JAYSON L. LUSK \\ Department of Agricultural Economics, Oklahoma State University, Stillwater, Oklahoma
}

\begin{abstract}
Consumers implicitly incorporate their perceptions of products into their decision processes, yet little research has explicitly focused on how those perceptions influence demand for meat. This study incorporates taste, health, and safety perceptions into a discrete choice experiment for meat products at a grocery store. Our results indicate that taste is the most important perception as a 1-unit increase in the perceived tastiness (on a -5 to +5 scale) of a food product leads to a $\$ 0.60$ increase in willingness to pay, whereas equivalent increases in perceived health and safety lead to $\$ 0.31$ and $\$ 0.21$ increases, respectively.
\end{abstract}

Keywords. Choice experiment, consumer perceptions, meat demand, willingness to pay

JEL Classifications. C83, D03, Q13

\section{Introduction}

Consumers are the notoriously fickle kingmakers of the market economy, and American meat products have been particularly susceptible to perception shifts over the past century. As Levenstein $(2012$, p. 162) explains, "The forces of modern science, industrialization, and globalization have combined with the 'omnivore's dilemma' and Americans' individualistic ethos to turn fear of food into something akin to a permanent condition of middle-class life." Upton Sinclair's The Jungle created support for government intervention in meat production as a result of food safety concerns (Ogle, 2013). In the middle of the 20th century,

The project was partially supported by the Oklahoma Agricultural Experiment Station, the Willard Sparks Endowment at Oklahoma State, and the Agricultural and Food Research Initiative Competitive Program of the U.S. Department of Agriculture, National Institute of Food and Agriculture (grant number 201567023-23134).

*Corresponding author: e-mail: trey.malone@okstate.edu 
perceptions regarding the unhealthiness of saturated fats reduced demand considerably for beef and eggs while simultaneously stimulating the market for olive oil and pasta (Schroeder and Tonsor, 2011; Teicholz, 2014). More recently, consumer fears regarding modern production practices have instilled new concerns surrounding the long-term safety of the American food system. As an example, demand for lean finely textured ground beef (LFTB) fell drastically when the media referred to the product as "pink slime" (Pruitt and Anderson, 2012).

Although consumer decision making has been frequently studied, meat demand studies have primarily focused on preferences for different attributes rather than the perceptions or beliefs consumers have about meat. Perceptions of environmental quality have been shown to alter policy recommendations for issues such as water quality and invasive species prevention (Adamowicz et al., 1997; Poor et al., 2001; Provencher, Lewis, and Anderson, 2012). Only recently has research incorporated the following method into discrete choice experiments for food as a way to distinguish between perceptions and preferences (Lusk, Schroeder, and Tonsor, 2014). For this study, participants complete a discrete choice experiment for an assortment of meat products. Then, we ask the participants to identify on a sliding scale how tasty, safe, and healthy they perceive each option in our choice experiment. From these results, we can describe how perceptions of the safety, health, and taste of meat products influence consumers' choices for meat products. From a nationwide discrete choice experiment with 1,000 respondents in the United States, we find that changes in perceptions yield substantial changes in willingness to pay (WTP), with perceived taste being the most important determinant perception for WTP. This information is particularly relevant for managers who might be considering the marginal benefits of different advertising strategies or new product innovations.

This article contributes to the literature by separating food perceptions from food preferences in the context of a choice experiment for meat (Lusk, Schroeder, and Tonsor, 2014). Specifically, we describe how consumers perceive the taste, health, and safety of food products in the grocery store. On average, we find that consumers perceive chicken breast as the most healthy and best-tasting meat alternative. Although consumers perceive beans and rice as the safest option, it is also the least tasty of the eight choices. Participants perceive deli ham to be, on average, one of the least healthy, least tasty, and least safe products. Pork chops and chicken wings are in the middle for each of the three categories. Consumers perceive all six meat products to be less safe than the two nonmeat products. By incorporating these findings into a random parameter logit model, we show how consumers consider the trade-offs associated among taste, health, and safety. Our results indicate that consumers are willing to pay more than twice as much for a 1-unit increase in taste than they are willing to pay for similar changes in health and safety perceptions. Additionally, through a series of counterfactual scenarios, we determine the impacts of changes in perceptions. 
This study is particularly relevant for policy makers and food companies. We provide strong evidence that taste is the most important perception for food choice, which helps explain the persistence of poor diets despite heightened pressure from policy makers for consumers to alter their food choices. As such, our findings suggest that other approaches might be necessary. Our findings are also important for agricultural industry organizations as we show that they might benefit from considering food perceptions because they have the potential to substantially influence consumer WTP.

In the following section, we discuss the previous research on how consumer perceptions influence product demand. We then explain the experimental design of our survey and the choice experiment method as it relates to changes in WTP from changes in consumer perceptions of taste, health, and safety. In Section 4, we describe the results of our model and their implications for managers who focus on consumer perceptions. Finally, we conclude with a discussion of the limitations of our study and suggestions for future research.

\section{Background}

Expected utility theory posits that the value of a purchase option is dependent on consumers' subjective beliefs (Lusk, Schroeder, and Tonsor, 2014; Savage, 1954). It is typically assumed that preferences, or values, are relatively stable, as approximately half of personality characteristics are attributable to genetics (Krueger et al., 2008). By contrast, it is more widely believed that perceptions are more malleable. Controlling for perceptions has the potential to generate significantly different estimates than models without perceptions (Adamowicz, Louviere, and Williams 1994; Marette, Roe, and Teisl, 2012).

By estimating the effects of perceptions on meat product choice, this article also contributes to the literature on demand for meat quality attributes (Schroeder and Tonsor, 2011). Previous research has indicated that nonprice characteristics have the potential to explain approximately three-fourths of the variability in meat demand (Tonsor and Marsh, 2007). Generally, quality attributes are divided between intrinsic, physical product attributes and extrinsic, abstract product attributes (Bernués, Olaizola, and Corcoran, 2003). Our focus is on consumer perceptions of extrinsic product attributes. As such, we focus our study on the three food perceptions of taste, health, and safety, which have been identified as the most important food values (Lusk and Briggeman, 2009).

The characteristic most commonly associated with food preferences is taste (Lusk and Briggeman, 2009; Mai and Hoffmann, 2012). We also include healthiness, as perceptions of health have become increasingly important for consumers, and there is evidence that health perceptions vary significantly (Binkley and Golub, 2011). Additionally, nutritional information can influence product demand (Kinnucan et al., 1997), indicating that perceptions have the potential to change. For our third perception, we include safety in our utility 
Table 1. Factors and Factor Levels for the Choice Experiment

\begin{tabular}{llllllllll}
\hline \hline Factors & Hamburger & $\begin{array}{l}\text { Beef } \\
\text { Steak }\end{array}$ & $\begin{array}{l}\text { Pork } \\
\text { Chop }\end{array}$ & $\begin{array}{l}\text { Deli } \\
\text { Ham }\end{array}$ & $\begin{array}{l}\text { Chicken } \\
\text { Breast }\end{array}$ & $\begin{array}{l}\text { Chicken } \\
\text { Wings }\end{array}$ & $\begin{array}{l}\text { Beans } \\
\text { and Rice }\end{array}$ & \multicolumn{2}{l}{ Tomato- } \\
Pasta
\end{tabular}

function. It has been shown that decoupling food risk perceptions from behaviors can improve the predictive power of experimental methods surrounding crises (Pennings, Wansink, and Meulenberg, 2002). Beliefs about food safety can also influence consumer WTP (Grunert, 2005; Lim et al., 2014), and previous studies have found that food safety events and recalls have small but statistically significant effects on demand (Piggott and Marsh, 2004; Tonsor et al., 2009). In the following section, we describe how we collected the data for the choice experiment and subsequent consumer perceptions. We also explain our empirical methods as it pertains to determining WTP.

\section{Data and Methods}

\subsection{Data}

Data were collected online as a part of the Food Demand Survey in January 2016, with 1,000 respondents in the United States. The Internet survey was administered by Survey Sampling Inc., which pays participants roughly $\$ 1.50$ in gift cards to complete the survey. Two portions of this survey are relevant for our analysis: a choice experiment and a consumer perceptions battery. In the choice experiment, participants were asked to choose between nine randomly ordered options (two beef, two pork, two chicken, two nonmeat alternatives, and a "none" option) for nine varying choice combinations where the product is uncorrelated with the price (i.e., a main effects orthogonal fraction factorial design). This design structure generated 27 choice questions, which were blocked into three sets of nine questions. Participants were randomly assigned into one of the three question blocks. Prior to responding to the choice experiment, participants were directed as follows: "Imagine you are at a grocery store buying the ingredients to prepare a meal for you or your household. For each of the nine questions that follow, please indicate which meal you would be most likely to buy." Each question provided the participant the choice between purchasing eight items at varying price levels and choosing to buy nothing. Table 1 shows the factors and factor levels available for each choice, and Figure 1 shows a sample question from this choice experiment. Each product was listed in a way that we 


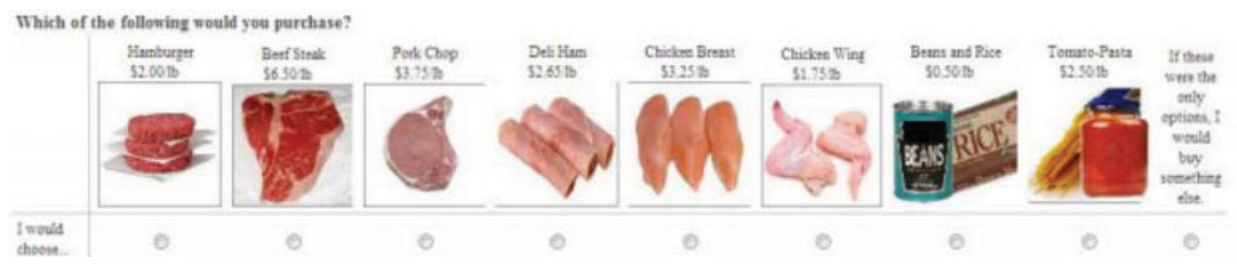

Figure 1. Sample Survey Question from the Choice Experiment

believed most consistently mirrored the grocery store; namely, the product prices were listed per pound, and there were equivalent nonmeat alternatives. For more detail on the design of the choice experiment, see Lusk and Tonsor (2016).

Immediately after the participant completed the choice questions, we asked three questions in a Likert-type scale for each food item, for a total of $8 \times 3=$ 24 additional questions. Previous research has indicated that consumers are most likely to value taste, safety, and health over other food values, so we included scales for each (Lusk and Briggeman, 2009). The first question asked, "How tasty or untasty do you consider the following products, where -5 is very untasty and +5 is very tasty?" In the second question, we asked, "How unhealthy or healthy do you consider the following products, where -5 is very unhealthy and +5 is very healthy?" Finally, we asked, "How unsafe or safe do you consider the following products, where -5 is very unsafe and +5 is very safe?" For each of these three questions, participants rated each of the eight choice options (steak, hamburger, chicken breast, chicken wing, ham, pork chop, beans and rice, and tomato pasta) on a sliding scale.

Although determining which products consumers perceive to be the most healthy, tasty, and safe clearly has value, what is likely to be more informative for agribusiness firms is the relative value of each of these food characteristics insofar as affecting consumer choice. By incorporating these perceptions into our choice experiment model, we can determine the premium that consumers are willing to pay if their perceptions are changed. In the following section, we describe how we incorporate perceptions into the consumer's utility function and how we estimate our discrete choice models.

\subsection{Methods}

The primary objective of this study is to determine how consumers incorporate these perceptions into the trade-offs they make in their purchasing decisions. That is, we are interested in how valuable perceived safety is relative to perceived taste or health. As such, we estimate a series of econometric models to determine these trade-offs. The modeling approach is based on McFadden's (1974) random utility model. The discrete choice experiment derives its explanatory strength from Lancaster's (1966) key insight that the goods' characteristics create the utility of a specific good relative to another good. When consumers choose what they 
want to eat, they reveal which meal characteristics they value relative to other characteristics. For our purposes, we specify participant i's utility of selecting meal choice $j$ in choice option $s$ as follows:

$$
U_{i j s}=\alpha \cdot \text { Price }_{j}+\beta_{j}+\tau_{1} \cdot S a f e_{i j}+\tau_{2} \cdot \text { Taste }_{i j}+\tau_{3} \cdot \text { Health }_{i j}+\varepsilon_{i j s},
$$

where Price $_{j}$ is the price of choice $j ; \alpha$ is the marginal (dis)utility of price of option $j ; \beta_{j}$ indicates the utility of product type $j$ not explained by safety, taste, or health perceptions; $S a f e_{i j}$ is participant $i$ 's safety rating for product $j$; Taste $e_{i j}$ is participant $i$ 's taste rating for product $j$; Healt $h_{i j}$ is participant $i$ 's health rating for product $j ; \varepsilon_{i j s}$ is the unobserved portion of the utility function; and all $\tau_{h}$ parameters represent the marginal utilities associated with changes in taste, health, and safety. The probability that consumer $i$ chooses meal $j$ in choice $s$ is

$$
\operatorname{Prob}(j \text { is chosen })=\frac{e^{V_{i j s}}}{\sum_{k=1}^{J} e^{V_{i j s}}},
$$

where $V_{i j s}$ is the systematic portion of the utility function determined by the attributes of meat $j$, individual-specific characteristics, and individual-specific perceptions.

To allow for additional heterogeneity beyond that present in differences in safety, taste, and health beliefs, we estimate a random parameter logit model and allow the alternative-specific constants, $\beta_{j}$, for each alternative to be random in the population in addition to the $\tau_{h}$ parameters. We estimate the random parameter logit model using simulated maximum likelihood with 1,000 Halton draws from univariate normal distributions. ${ }^{1}$

\section{Results}

Average values for each question can be found in Figure 2 (Pearson correlation coefficients can be found in the Appendix). There are larger differences in perceived healthiness across the meat products than there is in perceived taste or safety. Consumers perceive chicken breast to be the healthiest option, although the nonmeat alternatives were considered the safest. Steak is considered healthier and safer than hamburger, but there is no statistical difference between their perceived tastes $(\alpha=0.05)$. By contrast, deli ham is perceived to be the poorest tasting, least heathy, and most unsafe meat.

Interestingly, participants on average identify chicken breast as tasting (2.535) better than steak (2.262). Figure 3 shows a histogram of the difference between each respondent's perceptions of taste for chicken minus taste perceptions for

\footnotetext{
1 A methodological concern with incorporating perceptions into a discrete choice experiment is the potential for endogeneity. As such, we follow a method described in Malone and Lusk (2016) to test for endogeneity bias in our model. The Appendix includes a brief description of this method as it relates to the objectives of this article.
} 


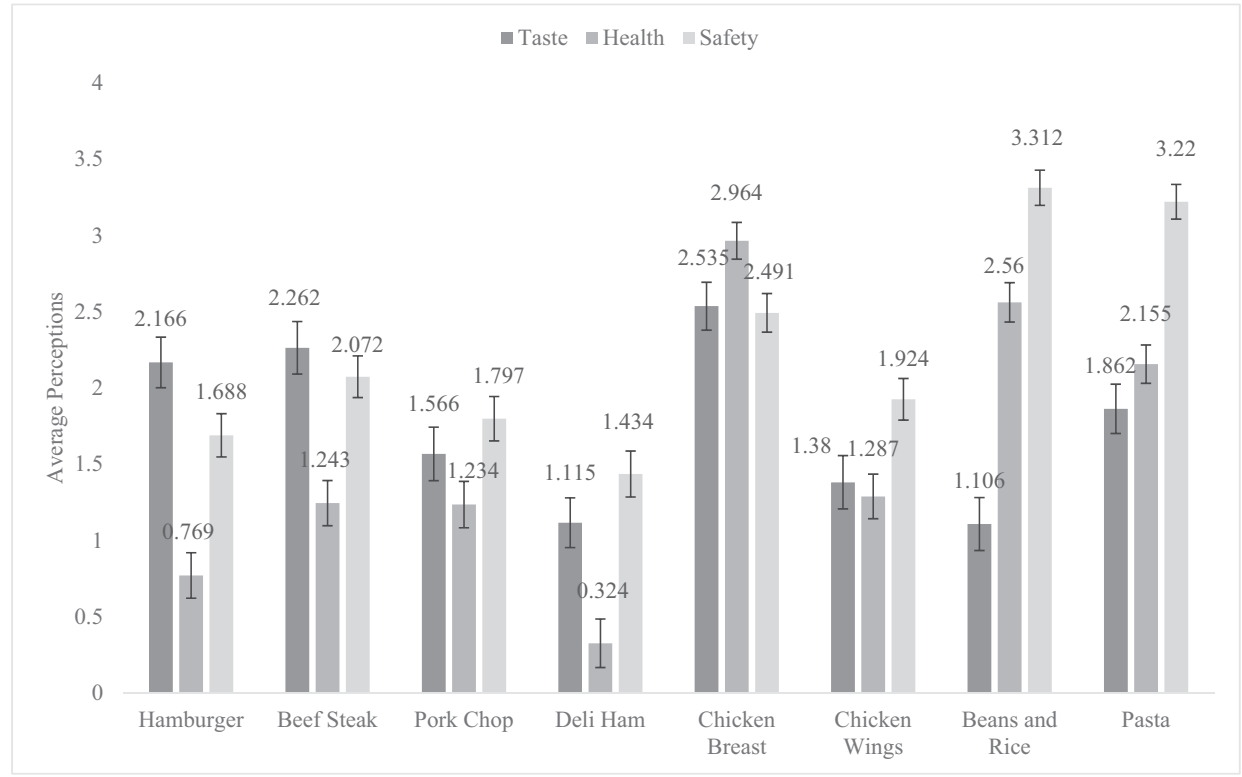

Figure 2. Average Perceptions for Taste, Health, and Safety (error bars represent $95 \%$ confidence intervals)

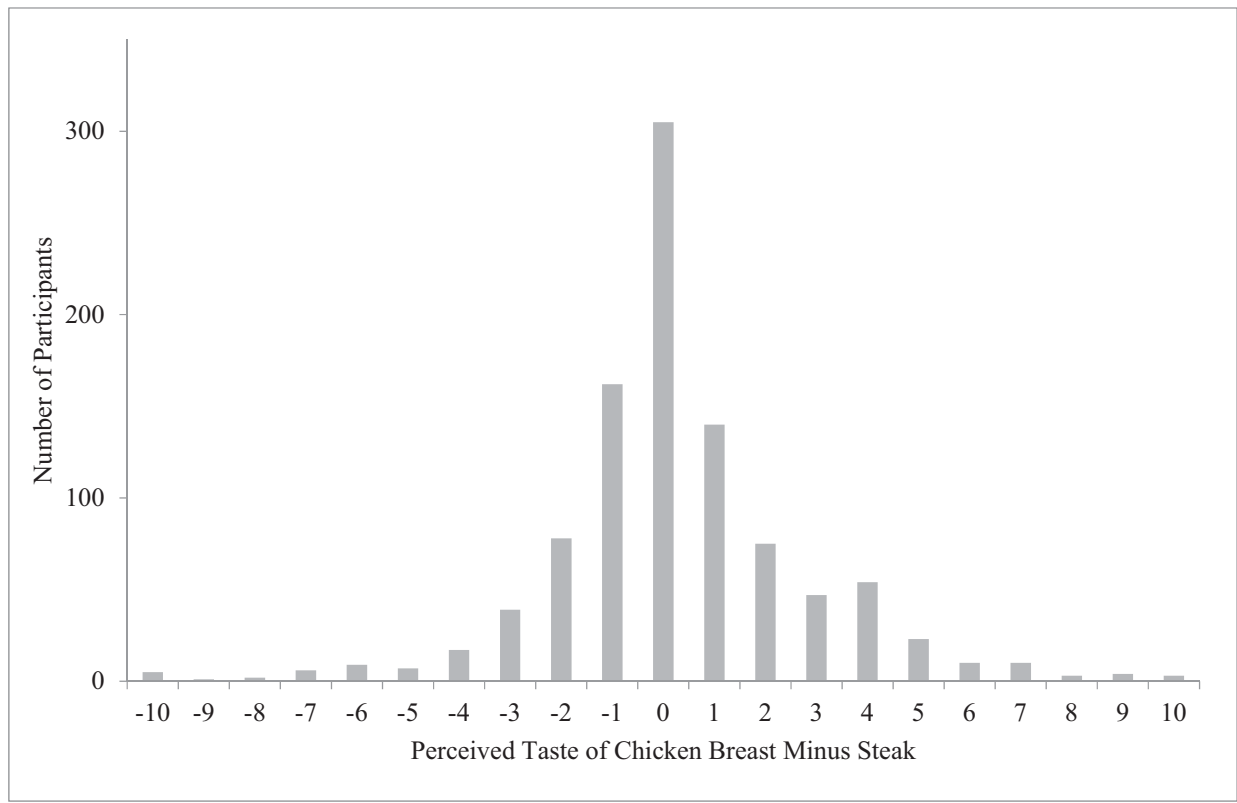

Figure 3. Histogram of the Difference between Chicken Breast and Steak Taste Perceptions (a negative value indicates that steak was perceived as tastier, whereas a positive value indicates that chicken breast was perceived as tastier) 
steak. Both the median and mode difference between taste perceptions is zero as 305 of the 1,000 participants indicate that steak and chicken breast are equally tasty. Consumers appear to be evenly divided on their perceptions of taste for steak and chicken as 326 participants in our sample prefer the taste of steak to the taste of chicken breast, while 369 participants prefer the taste of chicken breast to steak.

Table 2 shows the parameter estimates for basic multinomial logit (MNL) and random parameter logit models. From a likelihood ratio test, we can conclude that the random parameter logit model improves model fit over the basic MNL model $\left(\chi^{2}=3,862.3, \alpha=0.05, P<0.001\right)$. Additionally, adding parameters for perceptions into the model and allowing their parameters to be distributed normally improves model fit $\left(\chi^{2}=561.4, \alpha=0.05, P<0.001\right)$, Taken together, these findings indicate that separating consumer preferences from perceptions better explains consumer choice, and that perceptions influence each participant's choices differently. All parameters exhibit the expected signs; namely, the price parameter is negative, and increases in perceived taste, health, and safety all lead to increases in indirect utility. These parameter estimates indicate that a 1unit change in perceived taste leads, on average, to a significantly larger increase $(0.460)$ in overall utility than do changes in perceived health $(0.239)$ or safety (0.161). There is also more variation in perceptions of taste than in perceptions of health or of safety, as the estimated standard deviation for the random taste parameter is significantly larger than those for health or safety. Additionally, a $\$ 1$ increase in price leads to a 0.766 -unit decrease in indirect utility.

Each alternative-specific constant indicates the indirect utility for the characteristics of the product that were not captured by the product's perceived taste, perceived health, or perceived safety. The first coefficient in the model implies that, on average, consumers experience approximately 2.223 units of additional "happiness" from hamburger compared with "none" that is not explained by price, health, safety, or taste. Likewise, average consumers receive 2.894 more happiness units from steak than "none" when perceptions and prices are held constant. Thus, when price, perceived taste, perceived health, and perceived safety are all equal, steak provides $2.894-2.223=0.671$ more happiness units than hamburger to the average consumer. At the same time, the sizes of the estimated standard deviations indicate that taste preferences are significantly heterogeneous in our sample. For example, the model indicates that $68 \%$ of consumers have a preference for hamburger that is within 0.705 happiness units of the mean, or $2.223 \pm 0.705=[1.518,2.928]$ given that we assume preferences are normally distributed.

By dividing the parameter estimates of each perception by the price parameter, and then multiplying that value by -1 , we can convert the parameter estimates from utility space to WTP space. Figure 4 shows the WTP estimates for a 1-unit increase in taste, health, and safety perceptions. The estimates indicate that taste is the most important perception of the characteristics we examined as a 1-unit 
Table 2. Model Estimates that Include Parameters that Allow for Varying Levels of Taste Heterogeneity and Consumer Perceptions

\begin{tabular}{|c|c|c|c|c|}
\hline & \multicolumn{2}{|c|}{ Standard Multinomial Logit } & \multicolumn{2}{|c|}{ Random Parameter Logit } \\
\hline & & & \multicolumn{2}{|c|}{ Random Parameters } \\
\hline Hamburger & $2.688^{*}(0.060)$ & $1.979 *(0.064)$ & $2.167^{*}(0.085)$ & $2.223 *(0.092)$ \\
\hline Steak & $3.948 *(0.084)$ & $3.149 *(0.089)$ & $2.942 *(0.151)$ & $2.894 *(0.153)$ \\
\hline Pork chop & $2.282 *(0.065)$ & $1.550 *(0.069)$ & $1.612 *(0.098)$ & $1.789 *(0.099)$ \\
\hline Ham & $1.465^{*}(0.061)$ & $0.965^{*}(0.065)$ & $0.757^{*}(0.099)$ & $0.946 *(0.103)$ \\
\hline Chicken breast & $3.249 *(0.057)$ & $2.025 *(0.064)$ & $2.115^{*}(0.093)$ & $2.143 *(0.099)$ \\
\hline Chicken wing & $1.250 *(0.058)$ & $0.475^{*}(0.063)$ & $-0.053(0.107)$ & $0.109(0.111)$ \\
\hline Beans and rice & $1.302 *(0.058)$ & $0.131(0.068)$ & $-0.430 *(0.117)$ & $-0.245^{*}(0.116)$ \\
\hline Pasta & $1.963 *(0.071)$ & $0.821 *(0.079)$ & $0.528^{*}(0.132)$ & $0.582 *(0.138)$ \\
\hline Taste & & & & $0.460 *(0.025)$ \\
\hline Health & & & & $0.239 *(0.020)$ \\
\hline \multirow[t]{2}{*}{ Safety } & & & & $0.161 *(0.024)$ \\
\hline & & & \multicolumn{2}{|c|}{ Nonrandom Parameters } \\
\hline Price & $-0.556^{*}(0.011)$ & $-0.588^{*}(0.011)$ & $-0.764 *(0.014)$ & $-0.766^{*}(0.014)$ \\
\hline Taste & & $0.245^{*}(0.008)$ & $0.296^{*}(0.013)$ & \\
\hline Health & & $0.181 *(0.009)$ & $0.214 *(0.016)$ & \\
\hline \multirow[t]{2}{*}{ Safety } & & $0.112 *(0.010)$ & $0.128 *(0.018)$ & \\
\hline & & & \multicolumn{2}{|c|}{ Standard Deviations of Distributions } \\
\hline Hamburger & & & $1.040 *(0.065)$ & $0.705^{*}(0.083)$ \\
\hline Steak & & & $2.205^{*}(0.102)$ & $2.064 *(0.105)$ \\
\hline Pork chop & & & $1.166^{*}(0.082)$ & $0.680 *(0.103)$ \\
\hline Ham & & & $1.245^{*}(0.090)$ & $1.059 *(0.093)$ \\
\hline Chicken breast & & & $1.537^{*}(0.069)$ & $1.241 *(0.068)$ \\
\hline Chicken wing & & & $1.436 *(0.091)$ & $1.255^{*}(0.097)$ \\
\hline Beans and rice & & & $1.528^{*}(0.098)$ & $1.063 *(0.111)$ \\
\hline Pasta & & & $1.534 *(0.105)$ & $1.274 *(0.120)$ \\
\hline Taste & & & & $0.426^{*}(0.027)$ \\
\hline Health & & & & $0.194 *(0.036)$ \\
\hline Safety & & & & $0.295 *(0.028)$ \\
\hline $\begin{array}{l}\text { Log likelihood } \\
\text { function }\end{array}$ & $-16,996.4$ & $-15,518.7$ & $-13,868.2$ & $-13,587.5$ \\
\hline $\begin{array}{l}\text { Akaike information } \\
\text { criterion }\end{array}$ & $34,010.8$ & $31,061.4$ & $27,776.4$ & $27,221.0$ \\
\hline $\begin{array}{l}\text { Number of } \\
\text { observations }\end{array}$ & \multicolumn{4}{|c|}{9,000} \\
\hline $\begin{array}{l}\text { Number of } \\
\text { respondents }\end{array}$ & \multicolumn{4}{|c|}{1,000} \\
\hline
\end{tabular}

Notes: Number of participants $=1,000$. Number of choices observed $=9,000$. Asterisk $\left({ }^{*}\right)$ designates statistical significance at the $5 \%$ level. Numbers in parentheses are standard errors.

increase in the perceived taste of a product leads to a $60.22 \varnothing$ increase in the WTP for that product. Increases in health and safety perceptions led to smaller increases in WTP $(31.29 \phi$ and $20.94 \not$, respectively). Our results indicate that a 1-unit increase in perceived taste has about twice the impact on WTP as a 1-unit increase in health and about three times the impact on WTP as a 1-unit increase in 


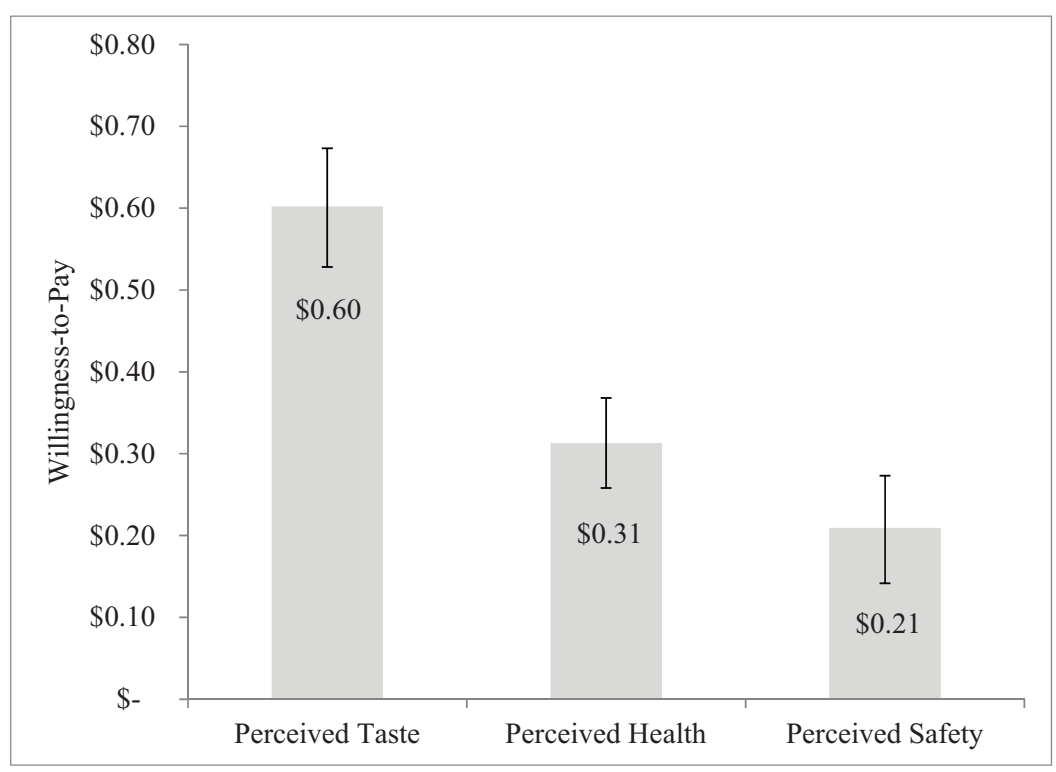

Figure 4. Increases in Willingness to Pay Associated with a 1-Unit Increase in Taste, Health, and Safety Perceptions (95\% confidence intervals calculated using the Krinsky-Robb method with 1,000 random draws)

perceived safety. Therefore, changes in perceived taste have a bigger impact than changes in perceived health, which in turn have a bigger impact than changes in perceived safety.

By estimating WTP values for each product at the mean perception scores, this model can generate additional insights. Mathematically, the average consumer WTP for product $j$ can be defined as follows:

$$
\mathrm{WTP}_{j}=\frac{\beta_{j}+\tau_{1} \cdot \text { Safe }_{j}+\tau_{2} \cdot \text { Taste }_{j}+\tau_{3} \cdot \text { Health }_{j}}{-\alpha_{\text {price }}},
$$

where standard errors are estimated following the method outlined by Krinsky and Robb (1986) via 1,000 normally distributed random draws (Table 3). These WTP values indicate that participants are willing to pay the most for steak $(\$ 5.95)$ and the least for beans and rice (\$1.83). Even though chicken breast is, on average, perceived as tastier and healthier than steak, participants are willing to pay less for chicken breast (\$5.77). By multiplying the WTP estimates for each perception unit by the average perceptions of each product and then dividing that value by the product's total WTP, we can determine what proportion of the product's WTP can be explained by the perceptions. For example, $36.8 \%$ of the WTP for steak can be described by taste, health, and safety perceptions. The remaining $63.2 \%$ of steak's WTP comes from some unidentified characteristic of steak. By contrast, perceptions of taste, health, and safety account for $76.9 \%$ 
Table 3. Willingness-to-Pay Estimates for Each Product Choice Based on Random Parameter Logit Model Estimates

\begin{tabular}{ll}
\hline \hline & With Average Perceptions ${ }^{\mathrm{a}}$ \\
\hline Hamburger & $\$ 4.80[4.54,5.05]$ \\
Steak & $\$ 5.95[5.58,6.30]$ \\
Pork chop & $\$ 4.04[3.78,4.30]$ \\
Ham & $\$ 2.30[2.01,2.59]$ \\
Chicken breast & $\$ 5.77[5.48,6.06]$ \\
Chicken wing & $\$ 1.77[1.47,2.07]$ \\
Beans and rice & $\$ 1.83[1.54,2.13]$ \\
Pasta & $\$ 3.22[2.87,3.57]$ \\
\hline \hline
\end{tabular}

${ }^{a}$ Willingness-to-pay estimates for model with perceptions generated assuming perceptions for each product are normally distributed around the averages identified in Figure 2.

Note: Numbers in brackets are $95 \%$ confidence intervals derived using 1,000 normally distributed random draws via the Krinsky-Robb method.

of consumer WTP for pasta. As such, these proportions make it clear that additional underlying characteristics that extend beyond taste, health, and safety perceptions make a steak a steak and a chicken breast a chicken breast.

\subsection{Counterfactual Scenarios}

Although we find a statistically significant relationship between WTP and perceived taste, health, and safety, it is of interest to consider how changes in perceptions affect choice. We now generate a series of counterfactual scenarios based on the average perceptions of taste, health, and safety. Figure 5 shows the estimated increases in WTP if perceptions for each product were to change to match the product with the highest mean perception. Chicken breast is perceived to be the best-tasting product in our choice set. If participants perceived hamburger to be as tasty as chicken breast, WTP for hamburger would increase by $\$ 0.22$. Deli ham has the largest potential to benefit from a change in perceived taste. As such, if deli ham were perceived to be as tasty as chicken breast, we would expect average consumer WTP to increase by $\$ 0.85$.

Our participants also indicate that they perceive chicken breast to be the healthiest option in our sample. Both beef products would generate substantial changes in WTP by increasing their perceived healthiness to that of chicken. For example, if hamburger had the same average health perceptions as chicken breast, WTP for hamburger would increase by $\$ 0.69$. Deli ham, however, would experience an $\$ 0.83$ increase in WTP if consumers were to believe it was as healthy as chicken breast. Even chicken wings would experience a $\$ 0.52$ increase in WTP through a perception change.

The nonmeat options are actually perceived as safer than the meat options. As such, if the average participant perceived hamburger to be as safe as beans and rice, WTP would increase $\$ 0.34$. Of all products, deli ham would benefit the most 


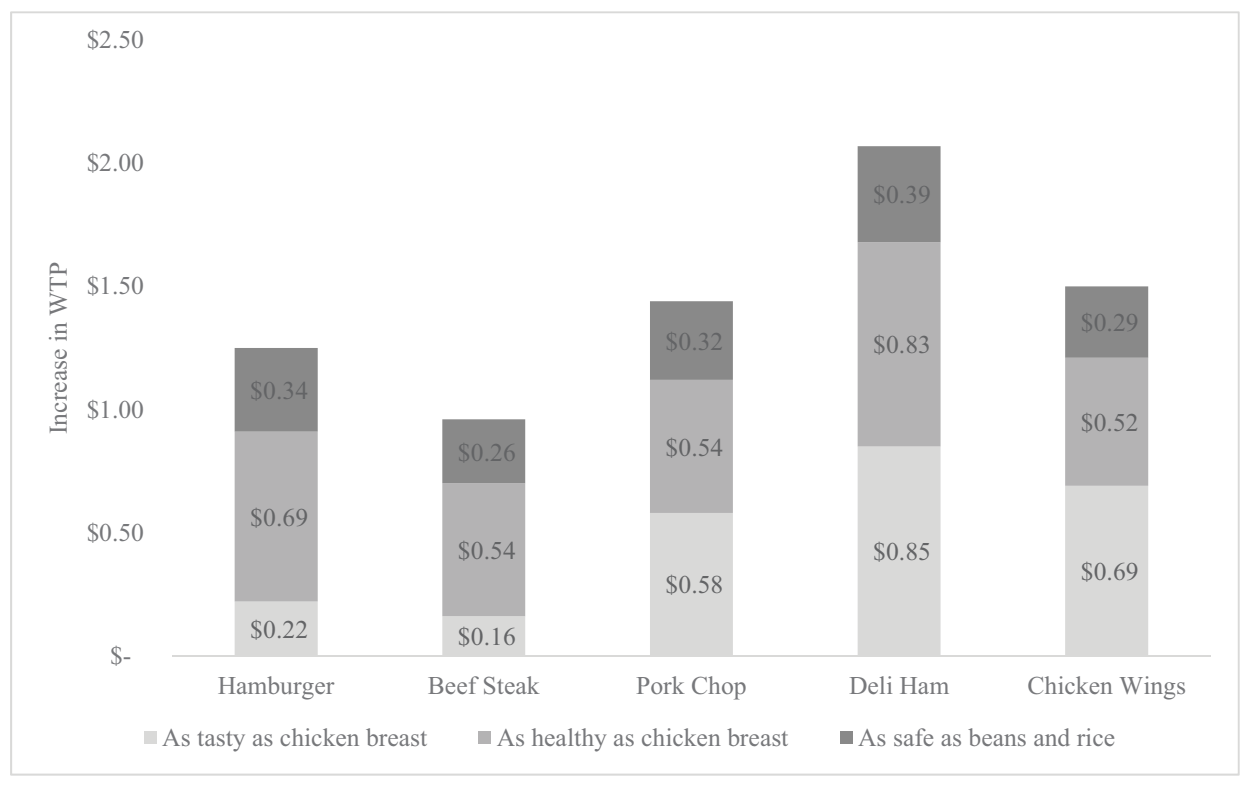

Figure 5. Hypothetical Increases in Willingness to Pay (WTP) when Taste, Health, and Safety Perceptions Are Maximized Relative to Other Products

by an increase in perceived safety to the level of beans and rice. In fact, our sample indicates that pork products are not very highly appreciated. As noted, deli ham is perceived to be the worst tasting, least healthy, and least safe alternative in the choice set. Those negative perceptions are costly. If participants were to perceive deli ham as equal to chicken breast in taste and health, and equal to the perceived safety of beans and rice, WTP for deli ham would increase by more than $\$ 2$.

\section{Conclusion}

This study focuses on changes in WTP derived from changes in perceptions of safety, taste, and health. Our findings support previous research regarding the economic value of safety and nutrition perceptions but extend them into the context of a choice experiment. Our results indicate that of the three perceptions we measured, consumers derive the most utility out of how they perceive a product's taste, rather than how healthy or safe they believe the product to be. At the same time, these findings cannot suggest that marketing materials would be best suited toward promoting health, as we do not know the cost of a 1-unit perception change.

Although this study provides an example of how consumers make trade-offs in the food marketplace, it is important to note the study's limitations. First, consumers do not strictly base their food choices on taste, health, and safety 
perceptions. Future research might incorporate different perceptions into the choice experiment. Additionally, our sample was representative of food choices in the United States. Other countries might have varying concerns regarding food preferences and perceptions. Consumers of the American food system might have taken food safety for granted relative to developing countries, for example, which might place a higher utility on perceived safety. Furthermore, other studies have identified that food perceptions might vary substantially by individual characteristics (Carels, Konrad, and Harper, 2007). As such, one might evaluate differences in food choices across those individual characteristics. Because values and perceptions are subjective, they are likely to vary based on underlying consumer characteristics (Grebitus and Dumortier, 2016). Future research might extend toward identifying the differences in how perceptions influence preferences across characteristics such as income, weight class, or age. It is also important to note that package sizes found in grocery stores vary in size because of natural between-animal variation. As such, a consumer confronted with choosing between meat products selects from an array of prices and quantities. Our study holds these quantity decisions constant to avoid potential confounds, but other studies might also choose to include quantity in the choice experiment framework. Regardless, our results show that part of food choices are linked to food perceptions.

Although our experiment focuses specifically on perceptions and preferences associated with meat products, this study has implications that extend further. Our findings have relevance for public policy as perceptions play a significant role in determining preferences. The most important perception, it appears, is taste. These results also have relevance for food companies, which routinely make advertising decisions from a limited budget. Although there might be value in promoting foods via attributes associated with health or safety, consumers ultimately still make choices linked predominately to their perceptions of taste.

\section{References}

Adamowicz, W., J. Louviere, and M. Williams. "Combining Revealed and Stated Preference Methods for Valuing Environmental Amenities." Journal of Environmental Economics and Management 26,3(1994):271-92.

Adamowicz, W., J. Swait, P. Boxall, J. Louviere, and M. Williams. "Perceptions versus Objective Measures of Environmental Quality in Combined Revealed and Stated Preference Models of Environmental Valuation.” Journal of Environmental Economics and Management 32,1(1997):65-84.

Bernués, A., A. Olaizola, and K. Corcoran. "Extrinsic Attributes of Red Meat as Indicators of Quality in Europe: An Application for Market Segmentation.” Food Quality and Preference 14,4(2003):265-76.

Berry, S., J. Levinsohn, and A. Pakes. "Automobile Prices in Market Equilibrium." Econometrica 63,4(1995):841-90. 
Binkley, J.K., and A. Golub. "Consumer Demand for Nutrition versus Taste in Four Major Food Categories.” Agricultural Economics 42,1(2011):65-74.

Carels, R.A., K. Konrad, and J. Harper. "Individual Differences in Food Perceptions and Calorie Estimation: An Examination of Dieting Status, Weight, and Gender." Appetite 49,2(2007):450-58.

Grebitus, C., and J. Dumortier. "Effects of Values and Personality on Demand for Organic Produce." Agribusiness 32,2(2016):189-202.

Grunert, K.G. "Food Quality and Safety: Consumer Perception and Demand.” European Review of Agricultural Economics 32,3(2005):369-91.

Kinnucan, H.W., H. Xiao, C.-J. Hsia, and J.D. Jackson. "Effects of Health Information and Generic Advertising on U.S. Meat Demand." American Journal of Agricultural Economics 79,1(1997):13-23.

Krinsky, I., and A.L. Robb. "On Approximating the Statistical Properties of Elasticities." Review of Economics and Statistics 68,4(1986):715-19.

Krueger, R.F., S. South, W. Johnson, and W. Iacono. "The Heritability of Personality Is Not Always 50\%: Gene-Environment Interactions and Correlations Between Personality and Parenting." Journal of Personality 76,6(2008):1485-522.

Lancaster, K.J. "A New Approach to Consumer Theory.” Journal of Political Economy 74,2(1966):132-57.

Levenstein, H. Fear of Food: A History of Why We Worry about What We Eat. University of Chicago Press, 2012.

Lim, K.H., W. Hu, L.J. Maynard, and E. Goddard. "A Taste for Safer Beef? How Much Does Consumers' Perceived Risk Influence Willingness to Pay for Country-of-Origin Labeled Beef." Agribusiness 30,1(2014):17-30.

Lusk, J.L., and B.C. Briggeman. "Food Values.” American Journal of Agricultural Economics 91,1(2009):184-96.

Lusk, J.L., T.C. Schroeder, and G.T. Tonsor. "Distinguishing Beliefs from Preferences in Food Choice." European Review of Agricultural Economics 41,4(2014):627-55.

Lusk, J.L., and G.T. Tonsor. "How Meat Demand Elasticities Vary with Price, Income, and Product Category." Applied Economic Perspectives and Policy 38,1(2016):1-39.

Mai, R., and S. Hoffmann. "Taste Lovers versus Nutrition Fact Seekers: How Health Consciousness and Self-Efficacy Determine the Way Consumers Choose Food Products." Journal of Consumer Behaviour 11,4(2012):316-28.

Malone, T., and J.L. Lusk. "A Method for Correcting for Endogeneity in Choice Experiments that Include Perceptions with Application to Beer Brands.” Agricultural Economics Working Paper Series, Stillwater: Oklahoma State University, 2016.

Marette, S., B.E. Roe, and M.F. Teisl. "The Consequences of a Human Food Pathogen Vaccine on Food Demand: A Calibrated Partial-Equilibrium Analysis of the U.S. Beef Market." Australian Journal of Agricultural and Resource Economics 56,3(2012): 366-84.

McFadden, D. "Conditional Logit Analysis of Qualitative Choice Behavior." Frontiers of Econometrics. P. Zarembka, ed. New York: Academic, 1974, pp. 105-42.

Ogle, M. In Meat We Trust: An Unexpected History of Carnivore America. Boston: Houghton Mifflin Harcourt, 2013.

Pennings, J.M.E., B. Wansink, and M.T.G. Meulenberg. "A Note on Modeling Consumer Reactions to a Crisis: The Case of the Mad Cow Disease." International Journal of Research in Marketing 19,1(2002):91-100. 
Petrin, A., and K. Train. "A Control Function Approach to Endogeneity in Consumer Choice Models." Journal of Marketing Research 47,1(2010):3-13.

Piggott, N.E., and T.L. Marsh. "Does Food Safety Information Impact U.S. Meat Demand?" American Journal of Agricultural Economics 86,1(2004):154-74.

Poor, P.J., K.J. Boyle, L.O. Taylor, and R. Bouchard. "Objective versus Subjective Measures of Water Clarity in Hedonic Property Value Models.” Land Economics 77,4(2001):48293.

Provencher, B., D.J. Lewis, and K. Anderson. "Disentangling Preferences and Expectations in Stated Preference Analysis with Respondent Uncertainty: The Case of Invasive Species Prevention." Journal of Environmental Economics and Management 64,2(2012):16982.

Pruitt, J.R., and D.P. Anderson. “Assessing the Impact of LFTB in the Beef Cattle Industry." Choices 27,4(2012):1-4.

Savage, L.J. The Foundations of Statistics. New York: Wiley, 1954.

Schroeder, T.C., and G.T. Tonsor. "Demand for Meat Quality Attributes." The Oxford Handbook of the Economics of Food Consumption and Policy. J.L. Lusk, J. Roosen, and J.F. Shogren, eds. Oxford: Oxford University Press, 2011, pp. 791-810.

Teicholz, N. The Big Fat Surprise: Why Butter, Meat and Cheese Belong in a Healthy Diet. New York: Simon and Schuster, 2014.

Tonsor, G.T., and T.L. Marsh. "Comparing Heterogeneous Consumption in U.S. and Japanese Meat and Fish Demand.” Agricultural Economics 37,1(2007):81-91.

Tonsor, G.T., T.C. Schroeder, J.M.E. Pennings, and J. Mintert. "Consumer Valuations of Beef Steak Food Safety Enhancement in Canada, Japan, Mexico, and the United States.” Canadian Journal of Agricultural Economics 57,3(2009):395-416.

\section{Appendix}

Table A1 shows the average taste, health, and safety scores for each choice, along with the sample standard deviations. These numbers are also displayed in Figure 2. Tables A2, A3 and A4 show the Pearson correlation coefficients across all choices. Generally, correlations were highest when comparing products from the same species.

Table A1. Average Scores for Perceptions of Taste, Health, and Safety

\begin{tabular}{llll}
\hline \hline & Taste & Health & Safety \\
\hline Hamburger & $2.166(2.680)$ & $0.769(2.405)$ & $1.688(2.294)$ \\
Beef steak & $2.262(2.784)$ & $1.243(2.392)$ & $2.072(2.212)$ \\
Pork chop & $1.566(2.830)$ & $1.234(2.457)$ & $1.797(2.343)$ \\
Deli ham & $1.115(2.635)$ & $0.324(2.568)$ & $1.434(2.433)$ \\
Chicken breast & $2.535(2.532)$ & $2.964(1.937)$ & $2.491(2.047)$ \\
Chicken wings & $1.380(2.823)$ & $1.287(2.359)$ & $1.924(2.201)$ \\
Beans and rice & $1.106(2.802)$ & $2.560(2.078)$ & $3.312(1.867)$ \\
Pasta & $1.862(2.611)$ & $2.155(2.036)$ & $3.220(1.835)$ \\
\hline \hline
\end{tabular}

Notes: Standard deviations are in parentheses. $\mathrm{N}=1,000$. 
Table A2. Pearson Correlation Coefficients for Perceived Taste

\begin{tabular}{|c|c|c|c|c|c|c|c|c|}
\hline & $\begin{array}{l}\text { Pork } \\
\text { Chop }\end{array}$ & Hamburger & $\begin{array}{l}\text { Beef } \\
\text { Steak }\end{array}$ & $\begin{array}{l}\text { Deli } \\
\text { Ham }\end{array}$ & $\begin{array}{l}\text { Chicken } \\
\text { Breast }\end{array}$ & $\begin{array}{l}\text { Chicken } \\
\text { Wings }\end{array}$ & $\begin{array}{l}\text { Beans } \\
\text { and Rice }\end{array}$ & Pasta \\
\hline Pork chop & 1 & & & & & & & \\
\hline Hamburger & 0.624 & 1 & & & & & & \\
\hline Beef steak & 0.601 & 0.735 & 1 & & & & & \\
\hline Deli ham & 0.558 & 0.516 & 0.481 & 1 & & & & \\
\hline $\begin{array}{r}\text { Chicken } \\
\text { breast }\end{array}$ & 0.501 & 0.603 & 0.544 & 0.435 & 1 & & & \\
\hline $\begin{array}{l}\text { Chicken } \\
\text { wings }\end{array}$ & 0.397 & 0.425 & 0.416 & 0.384 & 0.461 & 1 & & \\
\hline Beans and rice & 0.142 & 0.165 & 0.149 & 0.233 & 0.184 & 0.238 & 1 & \\
\hline Pasta & 0.211 & 0.263 & 0.258 & 0.297 & 0.334 & 0.243 & 0.421 & 1 \\
\hline
\end{tabular}

Notes: All Pearson correlation coefficients are significant and the $\alpha=0.01$ level. $\mathrm{N}=1,000$.

Table A3. Pearson Correlation Coefficients for Perceived Health

\begin{tabular}{|c|c|c|c|c|c|c|c|c|}
\hline & $\begin{array}{l}\text { Pork } \\
\text { Chop }\end{array}$ & Hamburger & $\begin{array}{l}\text { Beef } \\
\text { Steak }\end{array}$ & $\begin{array}{l}\text { Deli } \\
\text { Ham }\end{array}$ & $\begin{array}{l}\text { Chicken } \\
\text { Beast }\end{array}$ & $\begin{array}{l}\text { Chicken } \\
\text { Wings }\end{array}$ & $\begin{array}{l}\text { Beans } \\
\text { and Rice }\end{array}$ & Pasta \\
\hline Pork chop & 1 & & & & & & & \\
\hline Hamburger & 0.525 & 1 & & & & & & \\
\hline Beef steak & 0.526 & 0.721 & 1 & & & & & \\
\hline Deli ham & 0.521 & 0.532 & 0.455 & 1 & & & & \\
\hline $\begin{array}{r}\text { Chicken } \\
\text { breast }\end{array}$ & 0.443 & 0.302 & 0.373 & 0.245 & 1 & & & \\
\hline $\begin{array}{r}\text { Chicken } \\
\text { wings }\end{array}$ & 0.397 & 0.485 & 0.475 & 0.416 & 0.438 & 1 & & \\
\hline Beans and rice & 0.104 & 0.095 & 0.055 & 0.104 & 0.268 & 0.196 & 1 & \\
\hline Pasta & 0.189 & 0.233 & 0.177 & 0.285 & 0.218 & 0.232 & 0.425 & 1 \\
\hline
\end{tabular}

Notes: All Pearson correlation coefficients are significant and the $\alpha=0.01$ level, except for beef steak and beans and rice. $\mathrm{N}=1,000$.

Table A4. Pearson Correlation Coefficients for Perceived Safety

\begin{tabular}{|c|c|c|c|c|c|c|c|c|}
\hline & $\begin{array}{l}\text { Pork } \\
\text { Chop }\end{array}$ & Hamburger & $\begin{array}{l}\text { Beef } \\
\text { Steak }\end{array}$ & $\begin{array}{l}\text { Deli } \\
\text { Ham }\end{array}$ & $\begin{array}{l}\text { Chicken } \\
\text { Breast }\end{array}$ & $\begin{array}{l}\text { Chicken } \\
\text { Wings }\end{array}$ & $\begin{array}{l}\text { Beans } \\
\text { and Rice }\end{array}$ & Pasta \\
\hline Pork chop & 1 & & & & & & & \\
\hline Hamburger & 0.720 & 1 & & & & & & \\
\hline Beef steak & 0.631 & 0.634 & 1 & & & & & \\
\hline Deli ham & 0.592 & 0.542 & 0.610 & 1 & & & & \\
\hline $\begin{array}{r}\text { Chicken } \\
\text { breast }\end{array}$ & 0.566 & 0.577 & 0.567 & 0.465 & 1 & & & \\
\hline $\begin{array}{r}\text { Chicken } \\
\text { wings }\end{array}$ & 0.645 & 0.592 & 0.556 & 0.514 & 0.665 & 1 & & \\
\hline Beans and rice & 0.220 & 0.275 & 0.236 & 0.197 & 0.332 & 0.276 & 1 & \\
\hline Pasta & 0.307 & 0.329 & 0.277 & 0.262 & 0.334 & 0.301 & 0.652 & 1 \\
\hline
\end{tabular}

Notes: All Pearson correlation coefficients are significant and the $\alpha=0.01$ level. $\mathrm{N}=1,000$. 
As noted, endogeneity can potentially bias model estimation of choice models that include perceptions (Lusk, Schroeder, and Tonsor, 2014). To test for this potential endogeneity bias, we utilized the two-stage "control function" approach of Petrin and Train (2010) and more thoroughly described for the discrete choice experiment literature by Malone and Lusk (2016). Following an approach similar to Berry, Levinsohn, and Pakes (1995) who utilized prices for a product in one location as instruments for prices in another location, we considered models that used instruments based on the idea that although perceptions of other products are likely to be correlated with perceptions of a particular product, they are unlikely to be correlated with preferences of the product in question. For example, safety perceptions for chicken breast are likely to be correlated with safety perceptions for hamburger, but they are unlikely to be correlated with residual preferences for hamburger.

The estimation process requires two stages. For the first stage, we estimate regressions for all three beliefs for all eight products similar to this hamburger example:

$$
\begin{aligned}
& \text { Taste }_{\text {burger }}=f\left(\text { tast }_{\text {steak }}, \text { tast }_{\text {chop }}, \text { tast }_{\text {ham }}, \text { taste }_{\text {breast }}, \text { taste }_{\text {wing }}, \text { taste }_{\text {beans }},\right. \\
& \text { taste } \left._{\text {pasta }}\right)+ \text { e_taste }_{\text {burger }} \text {, } \\
& \text { Safe } e_{\text {burger }}=f\left(s a f e_{\text {steak }}, s a f e_{c h o p}, s a f e_{\text {ham }}, s a f e_{\text {breast }}, s a f e_{\text {wing }}, s a f e_{\text {beans }}\right. \text {, } \\
& \left.s a f e_{\text {pasta }}\right)+ \text { e_safe } e_{\text {burger }} \text {, } \\
& \text { Healt }_{\text {burger }}=f\left(\text { bealt }_{\text {steak }}, \text { healt }_{\text {chop }}, \text { health } h_{\text {bam }}, \text { health } \text { breast }_{\text {, }} \text {, health } h_{\text {wing }},\right. \\
& \text { healt } \left._{\text {beans }} \text {, health } h_{\text {pasta }}\right)+e_{-} \text {healt } h_{\text {burger }}
\end{aligned}
$$

This results in $8 \times 3=24$ regressions. Following Petrin and Train (2010), we take the error terms from these 24 equations and include them (in a second stage) in the respective utility functions of the multinomial logit (MNL). Although each parameter estimate is not necessarily descriptive on its own, what is important is that 179 of the 192 coefficients in this first stage are significant at the $\alpha=5 \%$ level. As such, it is apparent that beliefs for other products are good instruments for beliefs of a product in question.

In the second stage of our estimation process, we included the residuals from these estimated models as explanatory variables in the MNL model for each respective utility equation. Continuing the hamburger example, the second-stage function can be defined with eight equations similar to the following:

$$
\begin{aligned}
& U_{\text {burger }}=t_{\text {burger }}+a * \text { price }_{\text {burger }}+b * \text { tast }_{\text {burger }}+c * \text { bealt }_{\text {burger }} \\
& +d * \text { sa fet } y_{\text {burger }}+g_{1} * e_{-} \text {tast }_{\text {burger }}+g_{2} * e_{\_} \text {healt } h_{\text {burger }} \\
& +g_{3} * e \_s a f e t y_{\text {burger }} \text {. }
\end{aligned}
$$

Following Petrin and Train (2010), statistical significance of the $g_{1}-g_{3}$ parameters would indicate the presence of a problem with endogeneity. Table A5 lists estimations 
Table A5. Parameter Estimates Derived from the Residuals of the First-Stage Equations (i.e., the second stage of the control function approach)

\begin{tabular}{llrr}
\hline \hline & \multicolumn{2}{c}{ Perceptions } \\
\cline { 2 - 4 } Parameter & Health & \multicolumn{1}{l}{ Taste } & \multicolumn{1}{c}{ Safety } \\
\hline Hamburger & $-0.107^{*}(0.028)$ & $-0.003(0.026)$ & $-0.056(0.031)$ \\
Steak & $-0.025(0.030)$ & $-0.041(0.027)$ & $0.001(0.034)$ \\
Pork chop & $-0.034(0.033)$ & $0.055(0.030)$ & $-0.099^{*}(0.038)$ \\
Deli ham & $0.014(0.032)$ & $-0.023(0.030)$ & $-0.074^{*}(0.037)$ \\
Chicken breast & $0.049(0.026)$ & $-0.020(0.021)$ & $-0.094^{*}(0.027)$ \\
Chicken wing & $-0.007(0.031)$ & $0.104^{*}(0.028)$ & $-0.013(0.039)$ \\
Beans and rice & $0.064(0.033)$ & $-0.003(0.025)$ & $-0.038(0.040)$ \\
Tomato-pasta & $-0.168^{*}(0.034)$ & $0.071^{*}(0.029)$ & $0.017(0.045)$ \\
\hline \hline
\end{tabular}

Notes: Asterisk $\left({ }^{*}\right)$ designates statistical significance at the $5 \%$ level. Numbers in parentheses are standard errors.

Table A6. Parameter Estimates Derived from the Residuals of the First-Stage Equations (i.e., the second stage of the control function approach)

\begin{tabular}{lllll}
\hline \hline & $\begin{array}{l}\text { Original } \\
\text { Estimates (no } \\
\text { endogeneity } \\
\text { correction) }\end{array}$ & $95 \%$ CIs & $\begin{array}{l}\text { Corrected for } \\
\text { Endogeneity }\end{array}$ & $95 \%$ CIs \\
Parameter & $1.979^{*}(0.064)$ & {$[1.854,2.105]$} & $1.976^{*}(0.069)$ & {$[1.842,2.111]$} \\
Ground beef & $3.149^{*}(0.089)$ & {$[2.975,3.323]$} & $3.116^{*}(0.094)$ & {$[2.932,3.300]$} \\
Steak & $1.550^{*}(0.069)$ & {$[1.414,1.686]$} & $1.505^{*}(0.075)$ & {$[1.359,1.651]$} \\
Pork chop & $0.965^{*}(0.065)$ & {$[0.838,1.093]$} & $0.960^{*}(0.071)$ & {$[0.822,1.099]$} \\
Deli ham & $2.025^{*}(0.064)$ & {$[1.900,2.151]$} & $1.931^{*}(0.074)$ & {$[1.786,2.076]$} \\
Chicken breast & $0.475^{*}(0.063)$ & {$[0.353,0.598]$} & $0.295^{*}(0.072)$ & {$[0.154,0.436]$} \\
Chicken wing & $0.130(0.068)$ & {$[-0.003,0.263]$} & $-0.061(0.083)$ & {$[-0.225,0.102]$} \\
Beans and rice & $0.821^{*}(0.079)$ & {$[0.667,0.975]$} & $0.679^{*}(0.092)$ & {$[0.499,0.859]$} \\
Pasta & $-0.588^{*}(0.011)$ & {$[-0.611,-0.566]$} & $-0.589^{*}(0.011)$ & {$[-0.612,-0.567]$} \\
Price & $0.245^{*}(0.008)$ & {$[0.230,0.261]$} & $0.232^{*}(0.015)$ & {$[0.202,0.262]$} \\
Taste & $0.181^{*}(0.009)$ & {$[0.163,0.199]$} & $0.196^{*}(0.018)$ & {$[0.160,0.233]$} \\
Health & $0.112^{*}(0.010)$ & {$[0.092,0.132]$} & $0.156^{*}(0.020)$ & {$[0.117,0.195]$} \\
Nutrition &
\end{tabular}

Notes: Asterisk $\left({ }^{*}\right)$ designates statistical significance at the $5 \%$ level. Numbers in parentheses are standard errors. CI, confidence interval.

of the coefficients on the residuals from the estimated regressions. Out of 24 coefficients on the error terms entered into the MNL, only 7 are significant at the $\alpha=5 \%$ level. We take the low number of significant variables as an indication that there is little endogeneity present in the original model.

Most important is how much the endogeneity correction changes parameter estimates from the original model. In Table A6, we compare the parameter estimates from the MNL model in the article with the parameter estimates derived via our control function approach. This table indicates that the main estimates hardly change for most variables. In fact, the $95 \%$ confidence intervals all overlap for the model of 
original estimates and those corrected for endogeneity. Taken together, our estimates using this approach indicate that although perceptions for other products are good instruments for perceptions of a product in question, there is not much evidence of endogeneity. The main estimates hardly change for most variables in the endogeneitycorrected specification. Thus, for ease of discussion and interpretation, we report the "uncorrected" estimates in Table 2 of the article and the "corrected" estimates in Table A6. 